\title{
BLACK SEA INITIATIVE PROJECT FOR CIVIL MILITARY EMERGENCY PLANNING
}

$\mathrm{T}$ he Black Sea Initiative (BSI) project for Civil Military Emergency Planning was endorsed at an exploratory conference, initiated by Bulgaria held in Wiesbaden, Germany, in August 2004. The participating countries include the Black Sea littoral states - Bulgaria, Georgia, Moldova, Romania, Turkey and Ukraine. Though invited, Russia does not participate until now. The United States support the BSI providing the logistics and expertise.

The goal of the Initiative is to facilitate the cooperation among the participating countries and the coordination of all the available assets for any disaster.

It will focus on the issues of Black Sea commercial ports, the protection of population in port and harbor areas in the region, identifying primary risks/threats thereto, including the possible weapons of mass destruction considerations, chemical, biological, radiological, nuclear, high yield conventional explosives potentialities and natural disaster threats as well as and the consequential effects on the populations involved.

The parameters of the BSI will further be defined on the basis of the experience of its three working groups (Information/Management Technology, Standards and Procedures, Planning and Exercises) and the envisaged model top table exercises (TTE). The general methodology of the initiative is that civil protection TTE approach should be used.

The First BSI Conference was hosted by the Bulgarian Civil Protection State Agency in Varna, in October 2004. Five of the Black Sea littoral states including Bulgaria, Moldova, Romania, Turkey and Ukraine took part in the conference. The expert support was provided by the United States.

The Conference addressed common risks to populations in port and harbor areas of the Black Sea; the use of the international procedures established by the United Nations (UNOCHA-MCDA), NATO (EADRCC), and the European Union in current plans and the ways model table top exercises could be used to elevate and improve these plans.

The first BSI TTE “Tomis International 2005" will be held in September 2005 in Constanta, Romania. 